Territorios 38 / Bogotá, 2018, pp. 67-94

ISSN: 0123-8418

ISSNe: 2215-7484

Dinámicas sociales y reconfiguraciones territoriales contemporáneas

\title{
La configuración espacial de las clases alta y media en Cali: el caso de la urbanización Miraflores 1947-1950*
}

The Spatial Configuration of The Middle and High Classes in Cali: The Case of the Urbanization Miraflores (1947-1950)

A Configuração espacial da classe alta e média em Cali: o caso da urbanização Miraflores 1947-1950

\section{José Fernando Sánchez Salcedo*}

Recibido: 5 de febrero de 2017

Aprobado: 14 de agosto de 2017

Doi: http://dx.doi.org/10.12804/revistas.urosario.edu.co/territorios/a.5398

Para citar este artículo:

Sánchez, J. F. (2018). La configuración espacial de las clases alta y media en Cali: el caso de la urbanización Miraflores 1947-1950. Territorios, (38), 67-94. Doi: http://dx.doi.org/10.12804/revistas.urosario.edu. co/territorios/a.5398

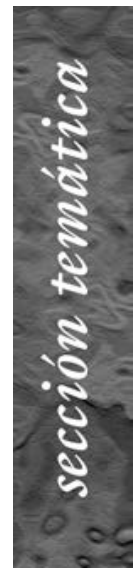

* Este artículo constituye un avance de los resultados del proyecto de investigación titulado "Caracterización de las clases medias y movilidad social en espacios urbanos. Un estudio comparado", financiado en la Convocatoria Interna $n .^{\circ}$ 6170 del 2015 y realizado conjuntamente por investigadores de la Universidad del Valle y de la Universidad de los Andes.

* * Profesor del Departamento de Ciencias Sociales de la Universidad del Valle. Comunicador social y doctor en Ciencias Politicas y Sociales de la Universidad Católica de Lovaina (Bélgica). Miembro del grupo de investigación Sociedad, Histórica y Cultura del Centro de Investigación de la Facultad de Ciencias Sociales y Económicas (CIDSE) 
Palabras clave

Historia urbana, configuración espacial, clasessociales, barrios, Cali.

Keywords

Urban History, Spatial Configuration, Social Classes, District.

Palavras-chave

História urbana, configuração espacial, classes sociais, bairros, Cali.

territarias 38

\section{RESUMEN}

Este artículo tiene como propósito estudiar el proceso de reconfiguración socio-espacial que se llevó a cabo en la ciudad de Cali durante la primera mitad del siglo xx, fruto de las transformaciones socioeconómicas que caracterizaron la región y que redundaron en un importante crecimiento de la población y en la consecuente demanda de vivienda urbana. Específicamente se centra en mostrar los primeros años del proceso de urbanización del barrio Miraflores, a partir de una estrategia metodológica que combina el análisis de fuentes documentales - como escrituras, fotos y mapas - y la historia oral, recogida mediante entrevista a algunos pobladores del barrio. El trabajo realizado muestra el proceso de segmentación que experimentó la ciudad en materia urbana a partir de la zonificación de sectores residenciales para estratos diferenciados, así como algunas características de sus pobladores, entre los cuales se cuentan comerciantes, empleados, ejecutivos de empresas e industrias de la época, y algunos extranjeros.

\section{ABSTRACT}

This article has the purpose to study the process of reconfiguration partner space which took place in the city of Cali during the first half of the twentieth century, the result of the socio-economic transformations that characterized the region and which resulted in a significant growth of the population and the consequent demand for urban housing. Specifically focuses on show, the early years of the process of urbanization of the Miraflores neighborhood, from a methodological strategy that combines the analysis of documentary sources as scriptures, photos and maps and oral history, collected by interviewing some of the residents of the neighborhood. The work shows the segmentation process that the city experiences in urban matters from the zoning of residential sectors to differentiated strata, as well as some characteristics of its inhabitants, among which are merchants, executive employees of companies and industries of the time and some foreigners.

\section{REsUmo}

Este artigo tem como propósito estudar o processo de reconfiguração socioespacial que se levou a cabo na cidade de Cali durante a primeira metade do século XX, fruto das transformações socioeconômicas que caracterizaram a região e que redundaram em um importante crescimento da população e na consequente demanda de vivenda urbana. Especificamente centra-se em mostrar, os primeiros anos do processo de urbanização do bairro Miraflores, a partir de uma estratégia metodológica que combina a análise de fontes documentais como escrituras, fotos e mapas e a história oral, recolhida mediante entrevista a alguns povoadores do bairro. O trabalho realizado mostra o processo de segmentação que experimentou a cidade em matéria urbana a partir do zoneamento de setores residenciais para camadas diferenciadas, assim como algumas características de seus povoadores, entre os quais se encontram comerciantes, empregados executivos de empresas e industrias da épica e alguns estrangeiros. 


\section{Introducción}

La emergencia de un conjunto de urbanizaciones dirigidas a sectores altos y medios en la ciudad de Cali, entre las décadas de los años veinte y cuarenta del siglo $\mathrm{Xx}$, fue el resultado de un proceso de reconfiguración socio-espacial de clase, estrechamente ligado al desarrollo industrial, al aumento de la población fruto de las nuevas oportunidades laborales y a la importante demanda que en materia de vivienda empezó a generarse para los trabajadores de las organizaciones empresariales.

El surgimiento paulatino de dos nuevos actores en el ámbito laboral: obreros y empleados de empresas públicas y privadas, creó las condiciones para un nuevo uso del suelo, que promovió la construcción en la ciudad y concitó el desarrollo de empresas que a través de un proceso poco planificado empezaron a expandir la ciudad hacia las zonas sur, oeste y norte.

En 1945 se creó Conélica Ltda., empresa que emprendió el proceso de urbanización del ejido de la Chanca, denominado por la constructora como Miraflores. Los lotes de la urbanización empezaron a venderse en 1947 y constaban en promedio de $400 \mathrm{~m}^{2}$. La nueva urbanización colindaría con el Barrio San Fernando, que fue inaugurado en $1928 \mathrm{y}$, al igual que este, estaría orientada a sectores de capas medias y altas de la ciudad.

El presente trabajo tiene como propósito llevar a cabo una primera aproximación al proceso de poblamiento y de urbanización del sector de Miraflores. El texto está dividido en cuatro partes. En la primera se hace referencia de modo referencial al marco conceptual que orientaría el estudio. En una segunda parte se describe la zona de Miraflores como parte de los ejidos de la ciudad. En la tercera, se hace referencia al contexto económico en que se desarrollan las urbanizaciones en la ciudad. Finalmente, la cuarta parte del texto se centrará en describir, para lo cual se apoyará en la consulta de escrituras y en un trabajo de historia oral sobre el proceso de poblamiento de la urbanización entre 1946 y 1950.

\section{La urbanización Miraflores entre la historia local y la urbana}

El estudio aquí propuesto se inscribe de manera general en una larga tradición de investigaciones que conciben la ciudad como "un nudo de relaciones sociales que al especializarse da forma a un lugar humanamente construido, a la vez que encuentra en dicho lugar una de sus fuerzas dinamizadoras" (Mejía, 2000, p. 16).

El núcleo específico de este ejercicio investigativo es aproximarse al proceso de urbanización de un barrio. Desde este punto de vista, se trata de una lectura microhistórica que, a través del estudio de un caso específico, da cuenta de los procesos de cambio urbano que se estaban llevando a cabo en la ciudad de Cali a mediados del siglo Xx. La historia barrial se inserta muy bien en el marco de una historia urbana, de la Universidad del Valle. Correo electrónico: jose.sanchez@correounivalle. edu.co, ORCID: http://orcid. org/0000-0002-7760-2267 territarias 38

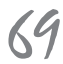


pues puede contribuir a "identificar las tramas más íntimas de una sociedad, rastreando la singularidad de ciertas prácticas sociales en un espacio territorial dado, a partir de una mirada que se entrecruza con una historia material del espacio ocupado y con la generación de representaciones mentales que engrosan el inventario diferenciado de los procesos y modelos culturales con los cuales se piensa y representa la ciudad" (Correa, 2006, p. 210).

En este sentido, a la vez que este artículo da cuenta del modo como las instituciones regulan y reglamentan la vida urbana mediante la consulta de instrumentos jurídicos como escrituras y planos urbanos, recoge el punto de vista de los individuos que habitan el espacio urbano, e interpreta y responde a su necesidad "por recordar e historiar los espacios donde merodeó su infancia" (Ramírez, 2005, p. 22).

Los individuos que viven en la urbanización Miraflores ocupan una posición en el espacio urbano, otorgada por su ubicación geográfica, pero sobre todo por el tipo de capitales con que cuentan. Ambos aspectos permiten incluir a los pobladores de la urbanización en el marco de una clase específica, en el sentido en que lo define Pierre Bourdieu, para quien las clases son "conjuntos de agentes que ocupan posiciones semejantes y que, situados en condiciones semejantes y sometidos a condicionamientos semejantes, tienen todas las probabilidades de tener disposiciones e intereses semejantes y de producir, por lo tanto, prácticas y tomas de posición semejantes" (Bourdieu, 1990, p. 284).
Además de compartir capitales y condiciones semejantes, los miembros de las clases sociales se inscriben en sectores urbanos que responden a clasificaciones socioespaciales específicas. En el caso particular de la urbanización Miraflores, esta ha sido definida para personas pertenecientes a capas altas y medias, tal y como es posible constatar más adelante en el plano de zonificación elaborado en 1949.

La tesis que se sustenta en este estudio es que la urbanización de la zona precordillerana del sur occidente de la ciudad, conocida hoy como Miraflores, hizo parte de un proceso de reconfiguración urbana y de uso del suelo, que buscaba segmentar la ciudad en zonas residenciales para capas sociales diferenciadas, y promovido por empresas que se conformaron en la ciudad para este fin a partir de la década de 1920. $\mathrm{Al}$ respecto señala Jacques Aprile-Gniset:

Así podemos identificar en los años 19201930 los efectos de una temprana migración intraurbana, caracterizada por un desplazamiento residencial del segmento social agrocomercial que dominaba la vida económica y la gestión política de la ciudad, resultando de esta tendencia el urbanismo de los mercaderes. Con los nuevos barrios claramente apartados en los extramuros, se manifestó una nueva segmentación social del espacio urbano, incluso grabada en el lenguaje de la prensa cuando hacia 1918-20 establecía desde la ideología una clara diferencia entre las parcelaciones residenciales y los barrios para obreros (Aprile-Gniset, 2012, p. 107). territarias 38 70 
Urbanizaciones como San Fernando, Granada, Peñón y después Versalles, Santa Isabel y Miraflores, se convirtieron en una opción para un nuevo sector de capas medias, compuesto por empleados de las nuevas organizaciones industriales que se ubicaron en la región; pero también fue una alternativa para desconcentrar el centro de la ciudad habitado tradicionalmente por comerciantes y sectores de élite.

\subsection{El origen ejidal de la urbanización Miraflores}

Las tierras de ejidos están especificadas en las Ordenanzas de descubrimiento, nueva población y pacificación de las Indias que emitió Felipe II en 1573, así como en la recopilación de Leyes de 1869. Estas tierras servirán para la recreación de las gentes de la ciudad y para el tránsito de los ganados hacia las dehesas. Además, los vecinos podrán extraer de ellas leña y frutos de pancoger (Pacheco, 1981, p. 84).

Uno de los aspectos clave para desentrañar la historia del poblamiento urbano pasa por conocer el proceso de evolución de la propiedad territorial en la ciudad, lo que lleva al viejo problema de los ejidos. Como lo señala Margarita Pacheco, la cuestión de los ejidos está estrechamente ligada "a la historia urbana, sobre todo, a partir del momento en que las ciudades fueron configurándose como tales, en un proceso jalonado por el desarrollo económico y político que experimentaba la nación (Pacheco, 1981, p. 77).
Hacia 1569, y durante el siglo XVII, el Cabildo de Cali empezó a otorgar solares en los ejidos de la ciudad, primero a indios yanaconas, mestizos, pardos y negros, y después a vecinos. En estas tierras se levantaron corrales, casas de habitación y estancias de ganado. El Cabildo entregaba las tierras en arrendamiento por diez años.

Las lomas precordilleranas situadas al occidente de la ciudad, y en donde actualmente se ubican los barrios de San Antonio, San Cayetano, Libertadores, Miraflores y San Fernando alto, hicieron parte de las tierras ejidales que se distribuyeron entre los siglos XVI y XIX. En el caso particular del barrio Miraflores, cuyos linderos se ubican entre las Lomas de la Chanca y Loma Pelada, las tierras fueron asignadas, en 1610, al contador Palacio Alvarado, quien las utilizó como estancia o latifundio ganadero.

Aunque no se encontró información al respecto, después de 1680 es posible que estas tierras ejidales hayan sido parte de las haciendas que darían continuidad al desarrollo económico de la ciudad durante los siglos XVIII y XIX, como las haciendas San Fernando y la de Loma Pelada.

A inicios del siglo XVIII, el pueblo solicitó las tierras de los ejidos al Cabildo y este decidió hacer una redistribución de aquellas aledañas a la ciudad, con el propósito de adjudicar terrenos a los más pobres de la población. El resultado de este proceso realizado entre 1706 y 1710 "no fue en modo alguno la recuperación de dichas tierras, sino el aceleramiento 
en las transacciones de compra-venta que se venían realizando en parte del espacio destinado ahora para los ejidos" (Pacheco, 1981, p. 82).

El problema de los ejidos continuó durante el siglo XIX y se extendió hasta el xx. Hacia 1840 se intentó nuevamente su recuperación; esta vez con el objeto de integrarlos a las rentas municipales. Para tal efecto, el Cabildo de Cali dio inicio a procesos de despojo a algunos hacendados que habían expandido sus propiedades a las antiguas tierras ejidales.

En 1860 se hizo un censo de las mejoras y viviendas ubicadas en tierras ejidales y se trabajó, por primera vez, en la recuperación de dichos terrenos en haciendas como Limonar, Cañaveralejo y Meléndez. En 1862 se volvieron a adjudicar terrenos ejidales en zonas como la Chanca y la Quebrada Sardinera; esta vez, los beneficiarios debían pagar el alquiler de la tierra cedida. "Así, por $40 \mathrm{~m}^{2}$, de terreno quebrado se cobraba en alquiler la suma de 20 centavos mensuales; si el terreno está sembrado de pasto guinea o pará, el arriendo sería de 40 centavos" (Pacheco, 1981, p. 91).

Una revisión de escrituras de propietarios y la asignación de tierras ejidales por parte del municipio a principios del siglo xx permitieron rastrear el poblamiento del sector de la Chanca (tabla 1).

En este proceso algunos arrendatarios se atrasaron en las cuotas establecidas y fueron reportados para ser intervenidos por las autoridades competentes. Para el

\section{territarias 38}

las personas identificadas fueron las siguientes (tabla 2).

Ambas tablas muestran la diversidad de personas que poblaban en esa época el sector, muchos de ellos, por sus apellidos, al parecer pertenecientes a un mismo grupo familiar. El proceso de asignación de ejidos continuó durante el transcurso de la urbanización del barrio, pues, como se mostrará más adelante, el área que comprende la urbanización constituía apenas una parte de la zona de las lomas de la Chanca y Loma Pelada, las cuales se fueron vendiendo y loteando paulatinamente hasta integrar lo que hoy se conoce como Miraflores.

\subsection{Desarrollo económico y crecimiento urbano durante el siglo $\mathrm{xx}$}

Un segundo aspecto clave para abordar el estudio del proceso de urbanización del barrio Miraflores es el acelerado crecimiento económico que vivió la ciudad entre 1920 y 1960, el cual se vio reflejado, como se verá más adelante, en un importante crecimiento de la construcción de vivienda en la ciudad. Así, la primera etapa del proceso de urbanización se llevó a cabo entre los años 1920 y 1930. Los establecimientos industriales más importantes de este momento fueron las trilladoras de café, la industria de textiles, las fábricas de bebidas y las tipografías.

En 1925 existían siete trilladoras de café, las cuales generaban el $40 \%$ del total 
Tabla 1. Lotes adjudicados a las zonas de la Chanca y la Sardinera, por área y canon de arrendamiento 1916

\begin{tabular}{|c|c|c|c|c|c|c|}
\hline & Nombre & Sexo & Canon anual & Superficie & Área & Ejido \\
\hline 1 & (sic: ilegible) & Sin identificar & 0,56 & 1600 & Rural & La Sardinera \\
\hline 2 & (sic: ilegible) Collazos & Sin identificar & 0,16 & 1600 & Rural & La Sardinera \\
\hline 3 & Martiniano Larrahondo & Hombre & 0,88 & 348 & Urbana & La Sardinera \\
\hline 4 & (sic: ilegible) Martínez & Sin identificar & 0,60 & 425 & Urbana & La Sardinera \\
\hline 5 & (sic: ilegible) Martínez & Sin identificar & 1,06 & 422 & Urbana & La Sardinera \\
\hline 7 & (sic: ilegible) Lourido & Sin identificar & 1,10 & 440 & Urbana & La Sardinera \\
\hline 8 & (sic: ilegible) Botes & Sin identificar & 0,46 & 180 & Urbana & La Sardinera \\
\hline 9 & (sic: ilegible) Orejuela & Sin identificar & 1,82 & 9131 & Rural & La Sardinera \\
\hline 10 & (sic: ilegible) & Sin identificar & 0,06 & 525 & Rural & La Chanca \\
\hline 11 & (sic: ilegible) De Mosquera & Mujer & 0,22 & 2203 & Rural & La Chanca \\
\hline 12 & (sic: ilegible) & Sin identificar & 0,30 & 113 & Urbana & La Chanca \\
\hline 13 & (sic: ilegible) Correa & Sin identificar & 0,22 & 88 & Urbana & La Chanca \\
\hline 14 & (sic: ilegible) & Sin identificar & 0,40 & 160 & Urbana & La Chanca \\
\hline 15 & (sic: ilegible) Holguín & Sin identificar & 0,82 & 327 & Urbana & La Chanca \\
\hline 16 & (sic: ilegible) Izquierdo & Sin identificar & 0,82 & 326 & Urbana & La Chanca \\
\hline 17 & (sic: ilegible) Izquierdo & Sin identificar & 0,90 & 363 & Urbana & La Chanca \\
\hline 18 & (sic: ilegible) Lloreda & Sin identificar & 0,50 & 199 & Urbana & La Chanca \\
\hline 19 & (sic: ilegible) Vásquez & Sin identificar & 1,38 & 550 & Urbana & La Chanca \\
\hline 20 & (sic: ilegible) & Sin identificar & 0,36 & 140 & Urbana & La Chanca \\
\hline
\end{tabular}

Fuente: Archivo histórico municipal de Cali. Contratos de arrendamiento de ejidos celebrados en 1916. Fondo Concejo. Folios 372-376 (sin tomo identificado aún).

del empleo en la urbe. En lo que respecta a la industria textil, la primera gran empresa fue La Garantía, que comenzó a funcionar en 1915. "En la década del 40, La Garan- tía ya tenía más de 1000 trabajadores. Le seguía en importancia la empresa Industria textiles de Colombia" (Ocampo, 1981, p. 134). 
Tabla 2. Lista de deudores por canon de arrendamiento - Ejido la Chanca 1917

\begin{tabular}{|l|l|l|}
\hline \multicolumn{1}{|c|}{ Nombre } & Sexo & Ejido \\
\hline José María Correa & Hombre & La Chanca \\
\hline Isabel Correa & Hombre & La Chanca \\
\hline Manuel Izquierdo & Hombre & La Chanca \\
\hline Rafael Izquierdo & Hombre & La Chanca \\
\hline Ricardo Izquierdo & Hombre & La Chanca \\
\hline Berenice Llanos & Mujer & La Chanca \\
\hline Pedro A. Moreno & Hombre & La Chanca \\
\hline Leticia Sarria & Mujer & La Chanca \\
\hline Agustín Soto & Hombre & La Chanca \\
\hline Pedro A. Salazar & Hombre & La Chanca \\
\hline Simón Vásquez & Hombre & La Chanca \\
\hline Rogerio Valencia & Hombre & La Chanca \\
\hline María Cruz Vernaza & Mujer & La Chanca \\
\hline Juan Bautista Vernaza & La Chanca \\
\hline Ascensión Vallecilla & La Chanca \\
\hline
\end{tabular}

Fuente: Archivo histórico municipal de Cali. Fondo Concejo. Tomo 200, año 1917, folios 301, 308-310, 372-379.

En lo que tiene que ver con la industria editorial, Carvajal y Cía., primera empresa del ramo, operó desde comienzos del siglo xx. Así mismo la industria tabacalera tuvo un importante desarrollo, pues "en los decenios de 1930 y 1940 Cali fue importante en la producción de cigarrillos, a través de la filial de la Compañía Colombiana de Tabacos. En 1945 la fábrica empleaba 251 trabajadores y producía 87,4 millones de cajetillas, el 26,1 \% de la producción nacional (Ocampo, 1981, p. 135).
La segunda etapa de industrialización de Cali se caracterizó por el surgimiento de nuevos sectores como el de producción de cementos - Cementos del Valle, 1939—, el de las empresas productoras de artículos de caucho - Croydon, 1937-, y el de reencauchaje de llantas - Goodyear, 1944-. Igualmente, por la aparición de empresas productoras de papel como Cartón de Colombia y Propal, establecidas en 1944 y 1961 respectivamente. 


\subsection{Población y estructura ocupacional}

El desarrollo industrial se vería reflejado en un importante aumento de la población y en la diversificación de la estructura ocupacional. Entre 1938 y 1964 la población localizada en la cabecera municipal creció significativamente y alcanzó una tasa promedio anual de $7,8 \%$ en 1951 .

En lo que respecta a la estructura ocupacional, el $27,4 \%$ de los ocupados trabajaba en el sector de servicios diversos y otros; el 27,9\%, en productos manufacturados (de estos el $23 \%$ correspondía a peones y obreros); el 12,2\% trabajaba en comercio y finanzas; el $10 \%$, en construcción; el 8,1\%, en transporte y comunicaciones; mientras que solo el $4 \%$ se dedicaba a la producción primaria (Ocampo, 1981, p. 143).

El incremento de la población y el desarrollo industrial estuvieron estrechamente relacionados con el auge de la construcción en la ciudad. El periodo más importante de crecimiento coincide con la bonanza económica de los años veinte. Luego de una corta disminución de la construcción, fruto de crisis económicas, desde la década del treinta comenzó un periodo de crecimiento constante y rápido que terminó a principios de los años 60 (tabla 3 ).
Tabla 3. Edificaciones en la ciudad de Cali, 1922-1963

\begin{tabular}{|c|c|c|c|}
\hline Año & $\mathbf{M}^{2}$ & Año & $\mathbf{M}^{2}$ \\
\hline 1922 & 16172 & 1943 & 133124 \\
\hline 1923 & 19074 & 1944 & 159327 \\
\hline 1924 & 20795 & 1945 & 139872 \\
\hline 1925 & 35444 & 1946 & 196361 \\
\hline 1926 & 64731 & 1947 & 130608 \\
\hline 1927 & 129658 & 1948 & 159259 \\
\hline 1928 & 160454 & 1949 & 203700 \\
\hline 1929 & 68939 & 1950 & 277335 \\
\hline 1930 & 23569 & 1951 & 224540 \\
\hline 1931 & 28771 & 1952 & 312532 \\
\hline 1932 & 43320 & 1953 & 273525 \\
\hline 1933 & 53965 & 1954 & 311073 \\
\hline 1934 & 69737 & 1955 & 361628 \\
\hline 1935 & 70091 & 1956 & 402064 \\
\hline 1936 & 77714 & 1957 & 396372 \\
\hline 1937 & 89595 & 1958 & 306085 \\
\hline 1938 & 84981 & 1959 & 482154 \\
\hline 1939 & 93567 & 1960 & 451136 \\
\hline 1940 & 83785 & 1961 & 456380 \\
\hline 1941 & 105207 & 1962 & 635334 \\
\hline 1942 & 109221 & 1963 & 694979 \\
\hline
\end{tabular}

Fuente: Ocampo, 1981 
Tal como lo señalan Jacques AprileGniset (2012) y Édgar Vásquez (2001), entre 1933 y 1951 surgieron alrededor de 35 nuevos barrios en la ciudad. Dentro de esta oferta es posible identificar diez barrios para las clases económicas altas al sur y al norte de la ciudad. Al sur: El Cedro (1951), Santa Isabel, San Fernando Nuevo, El Hipódromo (1950); y al norte: Versalles (1935), Juanambú (1937), Santa Mónica, Santa Teresita (1940), Campiña (1940), San Vicente (1940), los cuales fueron cambiando el paisaje y la fisionomía urbana de Cali. Así mismo, entre 1946 y 1951, según Édgar Vásquez (2001), el número de licencias de construcción expedidas por la Cámara de Comercio pasó de 936 a 1238 , lo que muestra el claro dinamismo de la construcción en el periodo estudiado.

\subsection{Transformaciones en la estructura ocupacional de la ciudad}

Según Ocampo (1981), el crecimiento económico relacionado con la generación de nuevas oportunidades de empleo implicó una fuerte redistribución de la estructura ocupacional de la ciudad (tabla 4).

En principio, es importante observar la paulatina disminución que tuvo la producción primaria entre 1918 y 1951 , así como el incremento de la producción manufacturera, la cual se ve reflejada en un importante aumento del personal de obreros. Así mismo, es de recalcar el dinamismo de los sectores de comercio y de servicios, lo que muestra un claro incremento de empleados privados y públicos.
Esta tendencia, como la señala Fresneda, va a ser general para el país y se va a caracterizar por el "decrecimiento del sector primario, particularmente el ubicado en la agricultura, silvicultura y pesca, y aumento del terciario. Estas transformaciones corren en paralelo con la progresiva concentración de la población en las áreas urbanas. La participación de los trabajadores del sector secundario (industria y construcción) presenta una disminución entre 1918 y 1938 y un modesto avance en los 40 años comprendidos entre este año y 1978, de 17 a $23 \%$ \% (Fresneda, 2009, p. 239).

Es posible que la emergencia de un importante sector de empleados haya sido una de las principales razones para que sociedades de carácter privado promovieran la construcción de la ciudad en suelo urbano para dichos grupos. Según Fresneda "entre 1918 y 1938 la proporción de trabajadores asalariados crece aceleradamente de 33 a $53 \%$ [...]. El crecimiento en la proporción de asalariados a partir de 1938 se explica por el aumento de empleados (administrativos y en ocupaciones del comercio y los servicios) y no de los clasificados como obreros" (2009, p. 241).

Este cambio en las categorías ocupacionales se vio reflejado en una clara reconfiguración de la estructura de clase para el año 1964 en la ciudad de Cali, tal y como lo muestran Bermúdez \& Fresneda (2016).

La importancia de la información citada en la tabla 5 radica en que señala cómo para 1964 es posible identificar en Cali un sector de clases medias, compuesto fun- 
Tabla 4. Estructura ocupacional de Cali, 1918-1980

\begin{tabular}{|l|r|r|r|r|r|r|r|r|r|r|}
\hline & \multicolumn{3}{|c|}{ Total ocupados según categoría } & \multicolumn{5}{|c|}{ Composición porcentual } \\
\cline { 2 - 13 } & 1918 & 1938 & 1951 & 1973 & 1918 & 1938 & 1951 & 1965 & 1973 & 1980 \\
\hline Población ocupada & 16553 & 42446 & 95782 & 276450 & & & & & & \\
\hline Producción primaria & 5160 & 8763 & 3787 & 9500 & 31,2 & 20,6 & 4,0 & 2,4 & 3,4 & 0,7 \\
\hline Producción manufacturera & & 11819 & 26759 & 66025 & & 27,8 & 27,9 & 23,4 & 23,9 & 28,7 \\
\hline Peones y obreros & 4691 & 5772 & 22064 & & 28,3 & 13,6 & 23,0 & 18,2 & & \\
\hline Construcción & & 3437 & 9591 & 18325 & & 8,1 & 10,0 & 7,1 & 6,6 & 5,1 \\
\hline Comercio y finanzas & 2154 & 5991 & 12070 & 60075 & 13,0 & 14,1 & 12,6 & 21,2 & 21,7 & 29,3 \\
\hline $\begin{array}{l}\text { Transporte y } \\
\text { comunicaciones }\end{array}$ & 320 & 2283 & 7787 & 12975 & 1,9 & 5,4 & 8,1 & 4,7 & 4,7 & 7,2 \\
\hline Servicios diversos y otros & 1517 & 8992 & 26213 & 67650 & 13,5 & 21,2 & 27,4 & 41,1 & 24,5 & 28,9 \\
\hline Se ignora & 2711 & 1161 & 9575 & 41900 & 12,1 & 2,7 & 10,0 & 0,1 & 15,2 & \\
\hline
\end{tabular}

Nota: Excluye oficios domésticos. Finanzas está incluido en servicios diversos

Fuente: (Ocampo, 1981: 143)

damentalmente por empleados; esto, de cierta forma, recoge la tendencia señalada ya por Ocampo (1981) y por Fresneda (2009) acerca del incremento del empleo asalariado en el país: "Entre 1918 y 1938 la proporción de trabajadores asalariados crece aceleradamente de 33 a $53 \%$ [...]. En contraste, entre 1938 a 1978 la proporción de asalariados aumenta lenta y modestamente para colocarse en torno al $60 \%$ " (Fresneda, 2009, p. 241). La emergencia de sectores medios sobre el papel supone, además, un proceso real de organización de empleados públicos y privados que inició en la década de los treinta con la conformación de un conjunto de federaciones y asociaciones en diversas ciudades del país.
La principal función de dichas organizaciones ${ }^{1}$ fue "propender por el engrandecimiento intelectual, moral, físico y pecuniario de los federados" (Antorcha, 1933). Para ello se enfocaron en una serie de acciones orientadas a contribuir a la formación intelectual de sus miembros, pero también a generar alternativas para mejorar sus condiciones de vida. Por esta razón, uno de sus principales proyectos durante buena parte de las décadas de los treinta y los cuarenta fue el de los programas de vivienda para empleados que, en ciudades como Bogotá, buscaba el apoyo de los gobiernos locales.

A pesar de carecer de datos para sustentarlo, es posible que organizaciones
${ }^{1}$ En Cali se conformó la Asociación de Empleados del Valle, que tuvo sede en Cali y que - sabemosorganizó el V Congreso de Empleados que se realizó en marzo de 1949. Uno de los temas que se debatió en dicho congreso fue el de las habitaciones para los empleados. Sin embargo, aquella discusión estuvo centrada en modificar los estatutos del Instituto de Crédito Territorial para permitir la participación de empleados en la estructura organizativa de la entidad y lograr que los préstamos del instituto incluyeran a los empleados (Congreso de Empleados de Colombia, 1950).

territarias 38

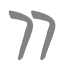


Tabla 5. Distribución de los ocupados de las clases alta, media y popular, desagregados por posiciones y fracciones de clase social, Cali, 1964

\begin{tabular}{|c|c|c|c|}
\hline \multirow[b]{2}{*}{ Posiciones de clase social } & \multicolumn{3}{|c|}{1964} \\
\hline & $\begin{array}{c}\text { Total } \\
\%\end{array}$ & $\begin{array}{c}\text { Hombres } \\
\%\end{array}$ & $\underset{\%}{\text { Mujeres }}$ \\
\hline Clase alta & 4,3 & 5,7 & 1,4 \\
\hline Directivos asalariados & 1,8 & 2,5 & 0,3 \\
\hline Directivos patronos & 2,5 & 3,2 & 1,0 \\
\hline Clase media & 27,9 & 26,3 & 31,6 \\
\hline Profesionales y técnicos asalariados & 7,3 & 7,2 & 7,7 \\
\hline Profesionales y técnicos independientes & 0,3 & 0,2 & 0,7 \\
\hline Empleados con funciones de dirección o control & \multirow{2}{*}{20,3} & \multirow{2}{*}{18,9} & \multirow{2}{*}{23,6} \\
\hline Empleados sin funciones de dirección o control & & & \\
\hline \multicolumn{4}{|l|}{ Pequeña burguesía en empresas de más de cinco trabajadores } \\
\hline \multicolumn{4}{|l|}{ Campesinos en explotaciones de más de cinco trabajadores ${ }^{*}$} \\
\hline Clase popular & 67,6 & 65,4 & 66,3 \\
\hline \multicolumn{4}{|l|}{ Obreros en ocupaciones artesanales } \\
\hline Supervisores y obreros calificados & 29,3 & 36,1 & 14,3 \\
\hline Otros obreros industriales no calificados & 1,5 & 2,0 & 0,3 \\
\hline Obreros agropecuarios & 3,2 & 4,4 & 0,4 \\
\hline Trabajadores domésticos & 12,1 & 1,0 & 36,8 \\
\hline $\begin{array}{l}\text { Trabajadores por cuenta propia, no agrícolas, en empresas de hasta cinco } \\
\text { trabajadores }\end{array}$ & 19,6 & 21,9 & 14,5 \\
\hline
\end{tabular}

* Incluye un bajo porcentaje no establecido de pequeña burguesía, que no ha sido desagregado en esta categoría.

** No se incluyen los valores porque no se desagregó entre los campesinos aquellos con más o menos de 5 trabajadores.

En total los campesinos no alcanzan a representar ni $2 \%$ del total de los ocupados urbanos.

Fuente: Bermúdez \& Fresneda, 2016. 
como la Federación de Empleados de Bogotá y la Asociación de Empleados del Valle auspiciaran el desarrollo de programas habitacionales para sus miembros o negociaran con sus empresas el apoyo de compra de terrenos para empleados, principalmente del nivel directivo.

\subsection{El surgimiento de las urbanizaciones}

Tal como sucedió en otras ciudades del país como Bogotá, Medellín y Barranquilla en las primeras décadas del siglo Xx, en Cali se llevó a cabo un proceso de migración intraurbana con el propósito de "realizar un desplazamiento residual de las élites agro-comerciales situadas en el centro de la ciudad a nuevos barrios hacia el norte, y el sur distanciados del centro" (Aprille, 2012, p. 107). Estas nuevas "parcelaciones residenciales" - como se les nombraba en la prensa local, según Aprille (2012)planteaban una clara separación socio-espacial con los barrios para obreros, que también empezaron a construirse en el mismo periodo.

Entre 1920 y 1927 se conformaron tres proyectos de parcelaciones suburbanas: el Peñón, Granada y San Fernando. La primera [parcelación] estaba ubicada hacia el oeste de la ciudad, entre el río Cali y el camino hacia Buenaventura; la segunda, entre el río y el viejo camino a Yumbo, y finalmente la tercera, al sur de la ciudad.

Las tres inauguran una nueva forma de crecimiento espacial "por saltos" y alojan a un fuerte grupo de comerciantes del centro: extranjeros inmigrantes o exiliados alemanes y polacos. La importancia de este proyecto radica en que dará la pauta para un proceso de segmentación socio-espacial que dividió la ciudad en sectores residenciales para capas medias y altas y barrios obreros, e incentivó la creación de nuevas empresas y urbanizaciones.

$\mathrm{Al}$ respecto señala Aprile-Gniset:

Con su localización y sus objetivos claramente especulativos se perdió la unidad geográfica del recinto que caracterizaba el ámbito de la urbe desde su fundación. Se interrumpió el modelo de la ciudad compacta y se inició la expansión fraccionada con parches sueltos tirados en el espacio agrario circundante [...]. Era el paso de un patrón de diseño predial a otro, auspiciado por un cambio que privilegiaba ahora un lote estrictamente residencial de menores dimensiones frontal y central (Aprile-Gniset, 2012, p. 107).

Al referirse al barrio San Fernando, López (citado por Aprile-Gniset, 2012), en el Almanaque de 1928, comenta que esta nueva urbanización "beneficiaría grandemente a las clases medias [...] por la necesidad que tiene de sostenerse dentro de las exigencias de su posición social y de educar bien a sus hijos en un ambiente de relativa holgura (López, 1928).

\section{La urbanización Miraflores}

En la siguiente foto (figura 1) se observa (al fondo) el lote de la urbanización Miraflores, con algunas casas; el internado de territarios 38 


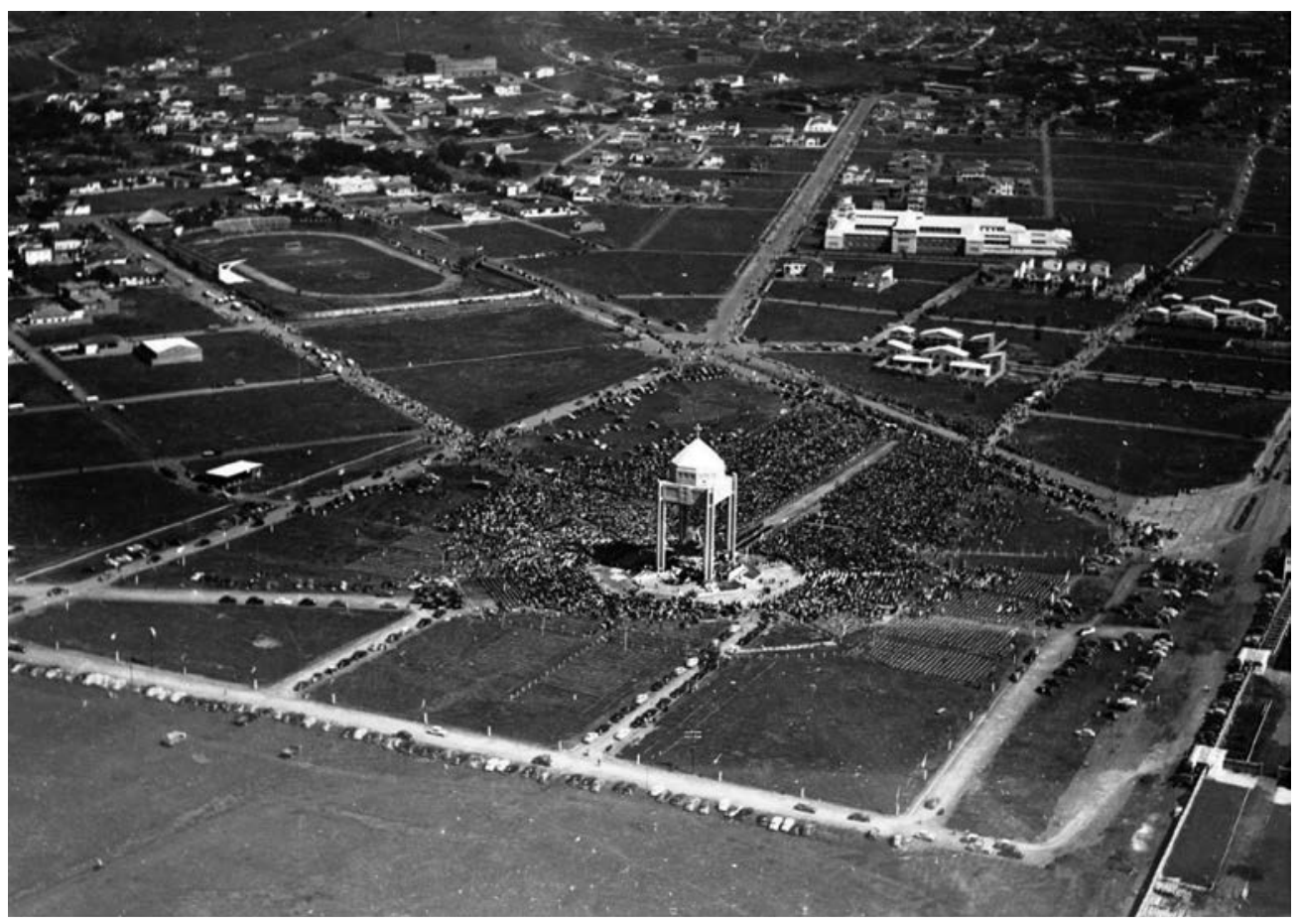

Fuente: Fotografía tomada por el capitán Uribe. Archivo Fotográfico de Cali.

las Adoratrices (hoy, Colegio Comfandi); y el trazado de la Herradura.

Según reza en la Escritura n. ${ }^{\circ} 2341$, radicada en la Notaría Primera de Cali, en 1945 se creó la constructora Conélica Ltda., empresa encargada de urbanizar terrenos ubicados en el sector de la Chanca. Dicha sociedad se constituye como sociedad comercial de responsabilidad limitada, con un plazo de duración de diez años. El objeto de la asociación era "la urbanización de terrenos, la construcción de edificios y la compra y venta de bienes raíces, en general, pero podrá ayudarse de otros negocios si así lo consideran sus socios" (Escritura n. ${ }^{\circ}$ 234l).

El capital inicial de la sociedad fue de 600000 pesos, divididos en 1200 acciones o derechos, cada una por un valor de 500 pesos. La conformación de los accionistas aportantes fue la siguiente (Tabla 6).

La Junta Directiva de la Sociedad, en su sesión ordinaria del 18 de noviembre de 1946, aprobó por unanimidad "autorizar al Gerente ordenar la propaganda necesaria, por la radio y la prensa sobre la venta de lotes y dar facilidades de pago que a su juicio crea convenientes. Que- 
da ampliamente facultado para aumentar o disminuir el área o cabida superficiaria de los lotes de terreno para efectos de las ventas" (Certificado del Secretario de la Sociedad Conélica Ltda.).

Tabla 6. Conformación de accionistas Conélica Ltda.

\begin{tabular}{|l|c|c|}
\hline \multicolumn{1}{|c|}{ Nombre } & $\begin{array}{c}\text { Número de } \\
\text { acciones }\end{array}$ & $\begin{array}{c}\text { Pesos } \\
(\$)\end{array}$ \\
\hline Inversiones Elica Limitada & 594 & 297000 \\
\hline Egidio Conssonni & 595 & 295500 \\
\hline Beatriz Córdoba & 1 & 500 \\
\hline Liliana Córdoba & 1 & 500 \\
\hline Mercedes Córdoba & 1 & 500 \\
\hline Ignacio Córdoba & 1 & 500 \\
\hline Carlos Plata & 1 & 500 \\
\hline Antonio Lloreda & 1 & 500 \\
\hline Luis E. Palacios & 1 & 500 \\
\hline
\end{tabular}

Fuente: Escritura n. ${ }^{\circ} 2341$ de 1945, Notaría Primera, Archivo Histórico de Cali.

En efecto los primeros lotes a los que se tuvo acceso empezaron a venderse en 1947. La escritura más antigua que se ha consultado es la del presbítero Julián Manzano, quien compró un lote a la empresa en ese año, según consta en la Escritura Pública n. ${ }^{\circ} 1499$ del 28 de julio de 1947. "El Lote adquirido es el marcado en el plano de la Urbanización "Miraflores" con el número 72, con extensión superficiaria de cuatrocientos sesenta y dos metros cuadrados $\left(462 \mathrm{~m}^{2}\right)$ inmueble que se halla ubicado en esta ciudad y cuyos linderos especiales son estos: por el Norte en extensión de veintidós metros (22) con el número 74 dentro de la misma urbanización, por el Sur en extensión de veintidós metros (22) con el lote número 27, la casa de la sociedad 'Sultana del Valle', por el Oriente en extensión de veintiún metros (21) con el resto del lote número 72 , y por el Occidente, en extensión de veintiún (21) con la calle primera en terrenos de la Urbanización".

En la distribución administrativa actual (figura 1), la urbanización Miraflores está ubicada en la Comuna 19, al sur occidente de Cali:

Figura 2. Mapa de Cali

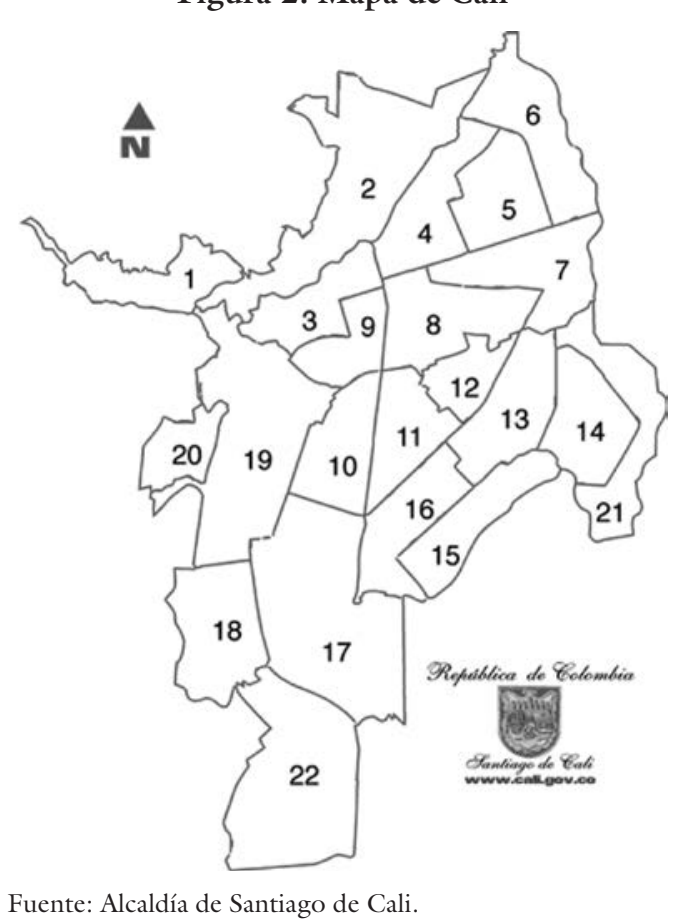


${ }^{2}$ Para esta y las citas textuales que siguen, con referencia a las escrituras públicas, se conserva el texto original.

\section{territarias 38}

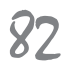

\subsection{El lote de la urbanización Miraflores}

A partir de la revisión de la escritura de algunos de los pobladores del barrio, fue posible rastrear a los antiguos dueños del terreno y determinar el área que adquirió la empresa para la construcción de la urbanización.

Agosto 10 de 1892: Escritura pública n. 425 - Notaría 2. ${ }^{a}$ de Cali ${ }^{2}$

Juan Ramón, José Antonio y María Jesús Orejuela, Magdalena y Juana Gertrudis Trigueros, está casada con Miguel Reyes, venden al Dr. Pablo María Aguilera, un lote de terreno situado en las inmediaciones de esta ciudad, en la loma de La Chanca, linderos: Oriente, camino público Cali a Popayán; Occidente y Sur, terrenos sueltos; Norte, mangas de herederos de Rafael Garcés y Antonio Collazos, y manga de Bernabé Labrada.

Diciembre 29 de 1896: Escritura pública n. ${ }^{\circ}$ 668 - Notaría 2. a de Cali

José Joaquín Aragón Orejuela vende al Dr. Pablo García A. un lote de terreno en el sitio de La Chanca, en punto de Tierras Blancas, linderos: Norte terreno ocupado por sucesores de Rafael Garcés y por Félix Rizo; sur, terrenos sueltos de los indivisos de los Cristales, Chanca y San Fernando; Oriente camino público de Cali a Popayán.

Febrero 26 de 1918: Escritura n. 60 - Notaría 1. ${ }^{a}$ de Cali

José Joaquín Aragón vende al Dr. Pablo
García, un derecho de tierra comprendido dentro de los linderos consignados en el punto segundo de este certificado.

Febrero 20 de 1942: Escritura n. 270 - Notaría 1. ${ }^{a}$ de Cali

Juicio de sucesión del Dr. Pablo García protocolizados fue liquidado [...] un lote de terreno situado en la carrera 15 de esta ciudad, alinderado: Norte, terreno del Club Noel en parte y terreno de la Loma de La Cruz, en parte; sur, predios del Dr., Calatrava, Gustavo Dové y Compañía Constructora Colombiana: Oriente, Avenida Tres de julio o carrera 15; Occidente terrenos denominados Los Cristales, La Chanca y San Fernando. Este lote fue evaluado en la suma de $\$ 35,000$ pesos y se adjudicó así:

A María Concha v. de García un derecho $\$ 17,500$.oo

A María Concha como heredera de su hijo José García \$2,187.50

A Delfina, Luis, Juan, María, Lucía, Olga y Teresa García Concha sendos derechos de $\$ 2,187.50$

Sus hijuelas fueron registradas el $\underline{30}$ de Enero de 1942 en libro de causas mortuorias. La partición se aprobó por medio de sentencia dictada por el Juzgado 4. Civil del Circuito, en Libro de causas mortuorias.

Septiembre 15 de 1942: Escritura n. ${ }^{\circ} 1430$ Notaría 2. ${ }^{a}$ de Cali

Juan y Luis García Concha venden a Eufemia Caicedo Ros un lote de terreno con cabida de 4.661 mts. cuadrados.

José Fernando SÁnchez SALCedo 
Septiembre 27 de 1943: Escritura n. 1557 Notaría 2. ${ }^{a}$ de Cali

Delfina García de Zamorano vende a Eufemia Caicedo Roa, un lote contiguo con cabida de 1000 mts. cuadrados.

Febrero 17 de 1944: Escritura n. 398 - Notaría 1. ${ }^{a}$ de Cali

María Concha v. de García vende a Egidio Conssoni, sus derechos que le fueron adjudicados en la sucesión de su esposo Pablo García A. En este acto concurre Mario de la Cadena y aprueba este contrato de compraventa, aprobación que se consigna por el proceso de venta que la Sra. Concha de García la había hecho y como tal venta la verifica el Sr. Consonni, el cual declara que ellos están a paz y salvo con el exponente, señor de la Cadena.

Mayo 22 de 1944: Escritura n. 1316 - Notaría 1. ${ }^{a}$ de Cali

Luis Pablo García Concha vende a Rogelio Suárez y Mario de la Cadena, los derechos que le sobren en el lote de terreno, deducido el lote vendido a Eufemia Caicedo Roa.

Julio 15 de 1944: Escritura n. 1828 - Notaría 1. ${ }^{a}$ de Cali

Juan García Concha vende a Mario de la Cadena y Rogelio Suárez C. los derechos que le sobre en el mismo lote de terreno deducido el lote vendido a Eufemia Caicedo Roa.

Agosto 2 de 1944: Escritura n. 2022 - Notaría 1. ${ }^{a}$ de Cali

Rogelio Suárez y Mario de la Cadena venden a Egidio Conssoni esos mismos derechos.
Marzo 17 de 1945: Juzgado 1. ${ }^{\circ}$ del Circuito Fueron registradas las hijuelas formadas en el juicio de división de ese globo de terreno, y se adjudicaron a Egidio Conssoni cinco lotes de terreno con cabidas de $11.581,32$; 9,880.oo; $1^{\circ}, 719.50 ;$ y 42,118.50 metros cuadrados y, a Eufemia Caicedo Roa un lote de 1000 mts. cuadrados y uno de $4.661 \mathrm{mts}$. cuadrados cada uno.

Marzo 23 de 1945: Escritura n. 806 - Notaría 1. a de Cali

Se protocoliza la anterior división del juicio de división aprobado por medio de sentencia del 9 de febrero de 1945.

Junio 1. ${ }^{\circ}$ de 1945: Escritura n. 1350 - Notaría 1. ${ }^{a}$ de Cali

Egidio Consonni transfiere a título de permuta a Eufemia Caicedo Roa, los lotes de terrenos n. ${ }^{\circ} 73$ y 75 con cabidas de 488,84 y 510,62 mts. cuadrados y la señora Caicedo Roa transfiere a Consonni el lote de terreno de 1000 mts. cuadrados que ella obtuvo dentro de la división establecida del lote.

Septiembre 11 de 1945: Escritura n. 2313 Notaría 1. ${ }^{a}$ de Cali

Egidio Consonni transfiere a título de permuta a Inversiones Elica Limitada, con un valor de $\$ 200,000$ los derechos de dominio equivalentes a la mitad de un lote de 86,000 metros cuadrados que hubo conforme los títulos que antecede. Excluye los lotes 73 y 75 transferidos a la señora Caicedo Roa y un lote de 4,000 mts. cuadrados. 
Con base en lo anterior se deduce que el lote que se urbaniza es de 86,000 metros cuadrados y su área corresponde a una parte del sector de la Chanca.

\subsection{El poblamiento del barrio Miraflores}

Tal como lo señala Margarita Pacheco (1981), la zona que hoy comprende el barrio Miraflores, hacía parte de terrenos ejidos, los cuales fueron tempranamente apropiados por los pobladores de la ciudad durante los siglos XVII y XVIII. En esta zona de ladera precordillerana se construyeron estancias y casas de habitación. En el siglo XIX, cuando la administración municipal intentó recuperar dichas tierras, pudieron constatar que una buena parte estaba en manos de pequeños y grandes propietarios o pertenecía a las haciendas que empezaron a florecer desde el siglo XVIII, lo cual cambió la dinámica productiva $\mathrm{y}$, con ello, el uso del suelo en los alrededores de la urbe.

A finales del siglo XIX la administración municipal, después de recuperar una parte de tierras de las haciendas para ejidos, decidió alquilar las tierras recuperadas para garantizar una entrada económica al erario. Este proceso continuó durante buena parte del siglo XX.

El surgimiento del proceso de construcción de la urbanización Miraflores, a finales de la década de 1940, constituyó una importante iniciativa de reordenamiento del espacio urbano que implicó, a la vez, territarias 38 un cambio en el uso del suelo con fines resi- denciales. Aunque solo hasta 1948 se creó un código urbano, en el plano de zonificación realizado por la Oficina del Plano de Cali, Miraflores quedó integrada a la zona de expansión residencial de la ciudad (figura 3). Aunque el plano retomaba algunas de las ideas del arquitecto Karl Brunner, contratado para tal fin, dejó entrever cambios significativos en la concepción del desarrollo urbano y social de la ciudad.

En lo que respecta a las zonas residenciales, la clasificación en tres categorías muestra una clara demarcación socio espacial: ordinaria, céntrica y exclusiva. La zona residencial ordinaria agrupaba los barrios populares de la ciudad y la atravesaba de oriente a occidente. La zona céntrica, por su parte, se dividía en dos grandes sectores, el occidental, que se ubicaba entre la colina de San Antonio y la Calle 10. ${ }^{\mathrm{a}}$, y el oriental, que se extendía entre las calles 14 y 22. Esta distribución coincidía con la ubicación socio espacial de principios del siglo XX. Finalmente, la zona residencial exclusiva integraba dos grandes zonas, una hacia el sur y otra hacia el oeste de la ciudad; "toda la zona prácticamente coincide con las expansiones de las clases media y alta de la ciudad durante el primer cuarto del siglo Xx" (Figueroa, 2013, p. 184).

La importancia de esta zonificación, más allá de sus aciertos y desaciertos, radica en que formalizó un proceso de configuración espacial de clase que venía gestando desde finales de la década del veinte en la ciudad, y mostró cómo el proceso de distribución urbana respondía más a los 
Figura 3. Plano de zonificación de la ciudad (sin fecha)

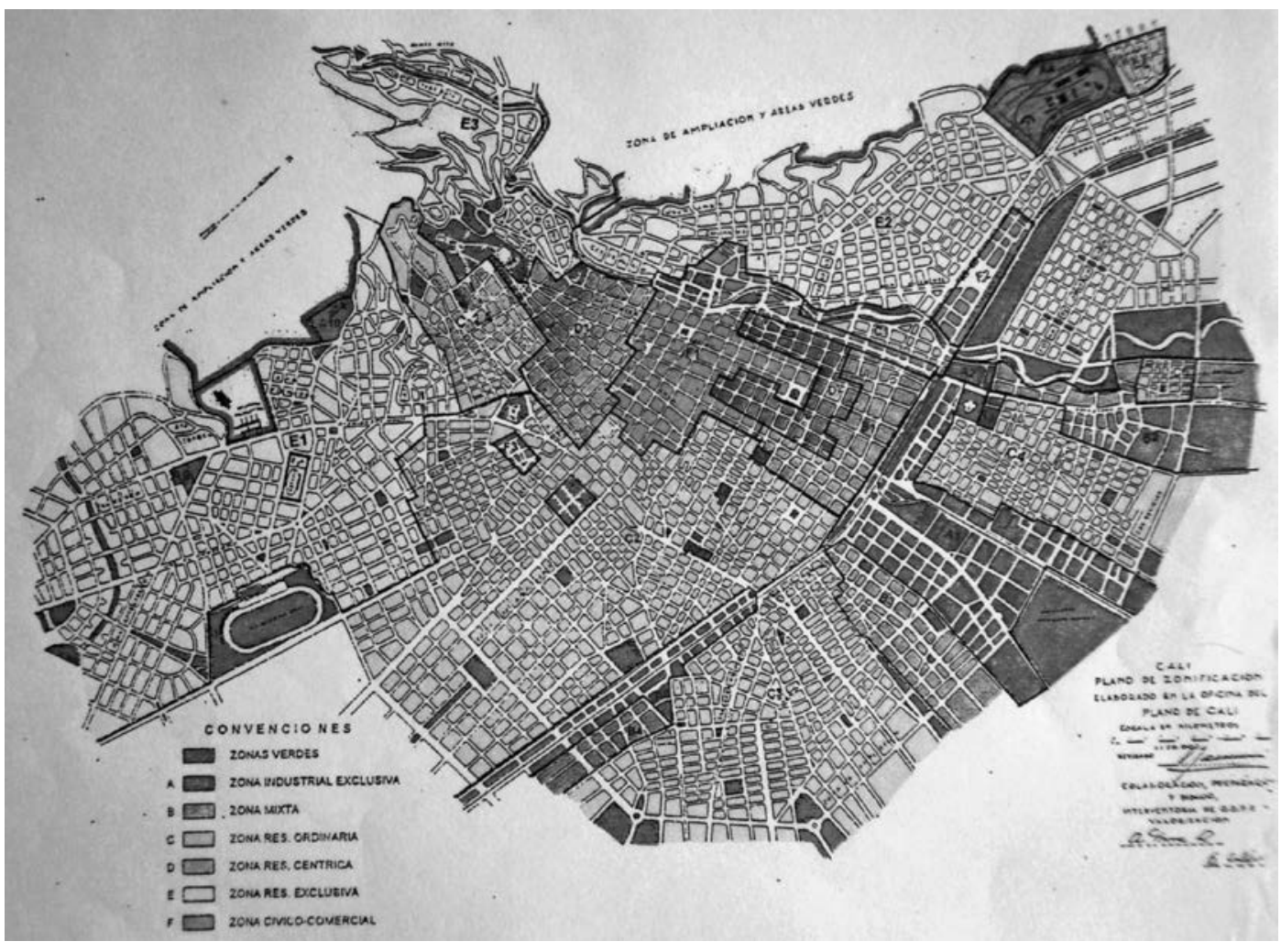

Fuente: Archivo del arquitecto Jaime Coronel.

Nota: En el plano la zonificación se reduce a siete zonas: A. zona de ampliación y áreas verdes, B. zona industrial exclusiva, C. zona mixta, D. zona residencial ordinaria, E. zona residencial céntrica, F. zona residencial exclusiva, y G. zona cívicocomercial.

intereses de los urbanizadores privados y al capital especulativo que a una organización racional del territorio.

El proyecto de lotes de Miraflores, al igual que otras urbanizaciones ${ }^{3}$ cuya comercialización tuvo lugar a finales de los cuarenta, empezó a venderse en 1947 (tabla 7). Si bien no fue posible encontrar el plano del proyecto, sí se logró conocer - gracias a la consulta de algunas escrituras- que el tamaño promedio de los lotes oscilaba entre los 260 y los $770 \mathrm{~m}^{2}$. Sus costos también variaban, de manera que era posible encontrar áreas de $330 \mathrm{~m}^{2}$ a 5820 pesos y otras de $371 \mathrm{~m}^{2}$ a 7420 pesos. Lo cierto es que para el costo de vida de la
${ }^{3}$ Como la urbanización Santa Isabel, que empezó a promocionar sus lotes en febrero de 1947, tal y como puede verse en los avisos que se publicaron en el periódico El Relatordurante los meses de febrero y marzo. 
Tabla 7. Compradores, costo y área de lotes de la urbanización Miraflores

\begin{tabular}{|c|c|c|c|c|}
\hline Comprador & Costo del lote & Número del lote & Área del lote & Escritura \\
\hline Julián G. Manzano & $\$ 7329$ & 72 & $462 \mathrm{~m}^{2}$ & $\begin{array}{l}\text { Escritura n. } .^{\circ} 1499 \text { del } 28 \text { de julio } \\
\text { de } 1947 \text {, Notaría Segunda }\end{array}$ \\
\hline Ramón A. Valencia & $\$ 12845,80$ & 21 & $642,29 \mathrm{~m}^{2}$ & $\begin{array}{l}\text { Escritura } n .^{\circ} 152 \text { del } 10 \text { de enero } \\
\text { de } 1949 \text {, Notaría Primera }\end{array}$ \\
\hline $\begin{array}{l}\text { Sarlata de Fiseh y Frida } \\
\text { de Fiseh }\end{array}$ & $\$ 7589,52$ & 33 & $421,64 \mathrm{~m}^{2}$ & $\begin{array}{l}\text { Escritura n. } .^{\circ} 197 \text { del } 24 \text { de enero } \\
\text { de } 1949, \text { Notaría Primera }\end{array}$ \\
\hline Jack Ferguson Wilkie & $\$ 13998,60$ & 103 & $770,70 \mathrm{~m}^{2}$ & $\begin{array}{l}\text { Escritura n. }{ }^{\circ} 407 \text { del } 16 \text { de febrero } \\
\text { de } 1949 \text {, Notaría Primera }\end{array}$ \\
\hline Pedro Roa & $\$ 8200,20$ & 27 & $420 \mathrm{~m}^{2}$ & $\begin{array}{l}\text { Escritura n } .^{\circ} 1212 \text { del } 21 \text { de abril } \\
\text { de } 1949, \text { Notaría Primera }\end{array}$ \\
\hline $\begin{array}{l}\text { Enrique Cano y la señora } \\
\text { Blanca Estela de Cano }\end{array}$ & $\$ 7420$ & 41 & $371 \mathrm{~m}^{2}$ & $\begin{array}{l}\text { Escritura n } .^{\circ} 1258 \text { del } 21 \text { de abril } \\
\text { de } 1949, \text { Notaría Primera }\end{array}$ \\
\hline Julián G. Manzano & $\$ 5820$ & 26 & $330 \mathrm{~m}^{2}$ & $\begin{array}{l}\text { Escritura n. }{ }^{\circ} 1334 \text { del } 5 \text { de mayo } \\
\text { de } 1949 \text {, Notaría Primera }\end{array}$ \\
\hline Luis E. Palacios & $\$ 9228,30$ & 40 y 41 & $615,22 \mathrm{~m}^{2}$ & $\begin{array}{l}\text { Escritura n. } .^{\circ} 1557 \text { del } 27 \text { de mayo } \\
\text { de } 1949 \text {, Notaría Primera }\end{array}$ \\
\hline $\begin{array}{l}\text { Olga Cecilia Peña de } \\
\text { Moreno }\end{array}$ & $\$ 10050$ & 15 & $670 \mathrm{~m}^{2}$ & $\begin{array}{l}\text { Escritura n. }{ }^{\circ} 1558 \text { del } 27 \text { de mayo } \\
\text { de } 1949, \text { Notaría Primera }\end{array}$ \\
\hline Ignacio Córdoba V. & $\$ 8704,80$ & 38 у 39 & $580,32 \mathrm{~m}^{2}$ & $\begin{array}{l}\text { Escritura n. }{ }^{\circ} 1559 \text { del } 27 \text { de mayo } \\
\text { de } 1949 \text {, Notaría Primera }\end{array}$ \\
\hline Víctor R. González C. & $\$ 5348$ & 28 & $267,40 \mathrm{~m}^{2}$ & $\begin{array}{l}\text { Escritura n. }{ }^{\circ} 1673 \text { del } 7 \text { de junio } \\
\text { de } 1949 \text {, Notaría Primera }\end{array}$ \\
\hline $\begin{array}{l}\text { Hernando Velásquez } \\
\text { Muñoz }\end{array}$ & $\$ 6000$ & 11 & $319,80 \mathrm{~m}^{2}$ & $\begin{array}{l}\text { Escritura n } .^{\circ} 1702 \text { del } 10 \text { de junio } \\
\text { de } 1949, \text { Notaría Primera }\end{array}$ \\
\hline $\begin{array}{l}\text { Germaine Morgan de } \\
\text { Bourguet y señores } \\
\text { Edmond Baca Kehrly y } \\
\text { Mariano Vukonich }\end{array}$ & $\$ 4334,40$ & 19 & $240,80 \mathrm{~m}^{2}$ & $\begin{array}{l}\text { Escritura n. }{ }^{\circ} 1951 \text { del } 2 \text { de julio de } \\
\text { 1949, Notaría Primera }\end{array}$ \\
\hline $\begin{array}{l}\text { José Escobar Lince, } \\
\text { gerente de la Compañía } \\
\text { Colombiana de Tabaco }\end{array}$ & & & $\begin{array}{l}\text { Casa de } 10 \\
\text { metros de } \\
\text { frente por } \\
22 \text { metros de } \\
\text { centro }\end{array}$ & $\begin{array}{l}\text { Escritura n } .^{\circ} 220 \text { del } 31 \text { de enero } \\
\text { de } 1950, \text { Notaría Segunda }\end{array}$ \\
\hline
\end{tabular}

ternitarios 38 Fuente: Archivo Histórico de Cali, escrituras de las notarías Primera y Segunda. 
época, su acceso solo era posible a personas con gran capital económico o a través de hipotecas con bancos a 20 y 25 años. Una tercera opción, tal y como se expone más adelante, fue la compra de lotes que hicieron algunas empresas, como la Colombiana de Tabacos, para que fueran pagados por sus propios empleados.

En lo que respecta a las personas que adquirieron los lotes, las escrituras no son muy específicas con la información de los compradores. Salvo la referencia a algunos extranjeros que se puede constatar por su cédula de extranjería, no es posible, con este instrumento, hacer una caracterización mínima de las personas que vivieron en la urbanización.

Para ahondar sobre el tipo de pobladores del barrio se optó por dos estrategias: primero, una metodología de taller cartográfico con propietarios, aprovechando las actividades de recuperación de la historia del barrio que hoy adelanta la Junta de Acción Comunal con el propósito de declararlo patrimonio arquitectónico de la ciudad. El taller que se trabajó, y que tuvo como criterio central convocar a propietarios, se centró en ubicar a los vecinos $\mathrm{y}$, en lo posible, su antigüedad en el barrio. La segunda estrategia se centró en realizar entrevistas con dos habitantes del barrio, cuyos padres adquirieron sus viviendas en Miraflores a finales de 1940 e inicio de 1950. El objetivo de la entrevista fue ahondar sobre el origen social de dichos pobladores a partir de aspectos como la descripción general de la familia, las ocupaciones de padres y hermanos, la procedencia, etc., lo que permitió identificar tres generaciones al interior de dichos núcleos familiares.

De este trabajo resultó un listado de los propietarios que adquirieron lotes y construyeron entre 1947 y 1950 (tabla 8). La información - aunque incompletapermite establecer un perfil general del tipo de personas que habitaron Miraflores y parte de la Herradura.

Tabla 8. Habitantes de Miraflores entre 1947 y 1950

Calle 5. ${ }^{a}$ - Calle $4 .^{a}$; Cra. 24A - Cra. 24C (Cra. 24B)

\begin{tabular}{|l|l|}
\hline \multicolumn{1}{|c|}{ Familia } & Actividad económica de alguno(s) de sus miembros \\
\hline Samaniego & Joyeros \\
\hline Kattan & Tienda \\
\hline Gallego & Restaurante Grill “Las Vallas” \\
\hline Barona & Taxis Barona \\
\hline Ramírez & Empleado de la Compañía Colombiana de Tabaco \\
\hline Norteamericanos & Sin información \\
\hline
\end{tabular}




\begin{tabular}{|l|l|}
\hline \multicolumn{1}{|c|}{ Familia } & Actividad económica de alguno(s) de sus miembros \\
\hline Naranjo Domínguez & Ferretería \\
\hline Rivera & $\begin{array}{l}\text { Empleado de la Compañía Colombiana de Tabaco; empleada } \\
\text { de Carvajal y Compañia }\end{array}$ \\
\hline Córdoba & Empleado de la Compañía Colombiana de Tabaco \\
\hline Sánchez Izquierdo & Empleado de la Compañía Colombiana de Tabaco \\
\hline Guevara & Sin información \\
\hline Espitia Celeita & Sin información \\
\hline Valencia & Constructor \\
\hline
\end{tabular}

Fuente: Taller de cartografía con los propietarios de Miraflores.

Tabla 9. Habitantes de Miraflores entre 1950 y 1960

Calle 2. ${ }^{a}$ Oeste - Calle 2A Oeste - Calle 2A; Cra. 24B

\begin{tabular}{|l|l|}
\hline \multicolumn{1}{|c|}{ Familia } & \multicolumn{1}{c|}{ Actividad económica de alguno(s) de sus miembros } \\
\hline Familia Castaño & Sin información \\
\hline Familia Quintián & Sin información \\
\hline Alberto Castaño & Sin información \\
\hline Cónsul de Haití & Diplomático \\
\hline Edificio Fanny & Arrendamiento de apartamentos \\
\hline Héctor Villegas & Dueño del Teatro Bolívar \\
\hline José Valencia & Comerciante y dueño de predios en Miraflores \\
\hline Cónsul de Noruega & Diplomático \\
\hline Héctor Villegas & Propiedad \\
\hline José Valencia & Propiedad \\
\hline Familia Trejos & Sin información \\
\hline Sr. Larsen & Gerente de Monail \\
\hline Sr. Felsberg & Gerente de Fruco \\
\hline Familia Correa & Sin información \\
\hline
\end{tabular}

Fuente: Taller de cartografía con los propietarios de Miraflores. 
Como es posible apreciar en esta pequeña muestra de dos cuadras de la urbanización Miraflores (tablas 8 y 9), las actividades económicas de sus dueños están centradas en las ramas del comercio, la construcción, la industria y los servicios. En dichos sectores productivos, las personas reseñadas se desempeñan como empresarios, comerciantes, empleados de instituciones públicas y privadas, y cuentapropistas. Todas estas ocupaciones se inscriben, como se vio, entre las actividades laborales que desempeñan las clases media y alta.

Según la conceptualización propuesta por Pierre Bourdieu para identificar posiciones de clase, es posible integrar al grupo de propietarios de la urbanización Miraflores en un mismo conjunto de agentes que comparten posiciones y condiciones relativamente semejantes, no solo por las actividades que desarrollan, sino también por su capital económico.

Vale la pena resaltar tres aspectos en esta urbanización: a) la existencia de dos consulados en el sector, b) la presencia de ciudadanos extranjeros y c) la existencia de edificaciones para el alquiler de apartamentos. Todos ellos dan pistas sobre las características del barrio, que parecen asemejarlo a su vecino San Fernando.

A partir de entrevistas informales realizadas a algunos de los propietarios durante el desarrollo de los talleres, se pudo establecer que algunas empresas, como la Colombiana de Tabacos, compraron lotes a la urbanizadora para sus empleados, lo que sin duda permitió que pese a su alto costo para la época, estos pudieran adquirirlos.

\section{Dos familias: los Roth y los Ararat}

\subsection{La familia Roth}

El señor Hans Roth llegó a Colombia en 1939 como delegado de la empresa Walter Utis Berger, la cual se encargaba de importar equipos suizos para la industria y la ingeniería. Antes había estado en España trabajando como botones de un hotel, pero con el inicio de la guerra civil española le tocó salir y a su regreso a Suiza fue reclutado por la empresa importadora y se le asignó la ciudad de Bogotá.

Mientras estaba en Colombia estalló la Segunda Guerra Mundial, lo que le obligó a permanecer en el país. En su estadía en Bogotá conoció a la señorita Lorena González, que se desempeñaba como mecanógrafa ${ }^{4}$ de la Colombiana de Seguros $^{5}$. Se casaron en 1942 y en 1943 tuvieron su primera hija, Isabel, y en 1945 nació la segunda, Juanita. En Bogotá vivieron en el barrio Chapinero y en Las Granjas. En 1947, aprovechando el desarrollo industrial, fue enviado a Cali para abrir una sucursal de la firma. En septiembre de ese año nació María, la tercera hija.

En Cali se ubicaron en el barrio El Peñón, en una casa al lado de la Escuela Isaías Gamboa. La oficina se abrió en un edificio en el centro de la ciudad. En 1949 decidieron comprar una casa y gracias a un amigo alemán se dieron cuenta de que estaban vendiendo lotes en la urbanización Miraflores. La casa que vieron les gustó.
${ }^{4}$ Durante su trabajo en la Colombiana de Seguros le tocaba llenar unas fichas de las casas del barrio San Fernando en Cali.

${ }^{5}$ Antes habia trabajado en el Real Banco de Canadá, llevada por su abuelo, quien se desempeñaba como cajero $y$ antes de esto habia trabajado como telégrafo en Manizales. tersitarios 38

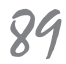


Isabel inició sus estudios en el colegio la Sagrada Familia. Luego se pasó al recién creado Colegio Bolívar donde, junto con sus dos hermanas estudiaron la primaria y el bachillerato.

Isabel se graduó en 1961. Hizo parte de la primera promoción del colegio Bolívar. Se presentó a la Universidad del Valle a estudiar Arquitectura. Se graduó en 1967 y en ese mismo año se casó con Álvaro, uno de sus compañeros de estudio. Después de doce años de matrimonio, en 1979 se separó y se devolvió a su casa materna. Isabel tuvo que hacerse cargo de la crianza y el mantenimiento de sus hijos, por eso trabajó por muchos años como docente y como dibujante de un arquitecto. Pasó por muchas dificultades económicas. Sin embargo, a finales de los noventa inició estudios de paisajismo y una vez graduada empezó a trabajar de manera independiente. De ese matrimonio quedaron dos hijos: Adalberto (1968) y Xiomara (1970). El primero estudió comunicación social y la segunda, Arquitectura; ambos en la Universidad del Valle.

Hoy en día Isabel vive todavía en Miraflores. Comparte la casa con su hija Xiomara, quien les compró a sus dos tías lo que les correspondía como herencia. Isabel ocupa su tiempo en sus proyectos arquitectónicos como trabajadora independiente y en actividades cívicas en la Junta de Acción Comunal del barrio.
Figura 4. Cra. 24B del barrio Miraflores en 1949

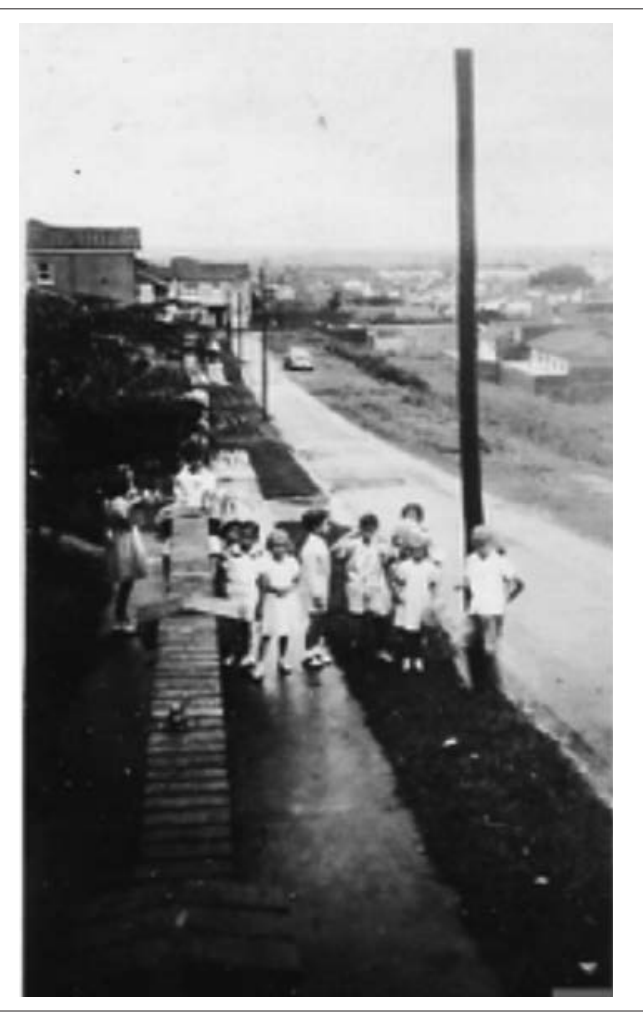

Fuente: Archivo de la arquitecta Silvia Schiess.

\subsection{La familia Ararat}

Don Roberto Ararat, abogado, de Puerto Tejada Cauca, llegó a Cali en 1948 cuando estaba recién casado, huyendo de Puerto Tejada, donde fue perseguido por sus actividades políticas con el célebre parlamentario liberal Natanael Díaz. Don Roberto ejerció su profesión como abogado hasta el 
2005, periodo en el cual litigó, fue concejal y representante a la Cámara por el partido liberal y por la ANAPO, a la que se afilió de la mano de doña Cecilia Muñoz (pelusa), la líder anapista caleña, quien también vivió en Miraflores.

El señor Ararat se radicó inicialmente en el barrio Fray Damián, donde alquiló un cuarto. Después, cuando pudo ubicarse laboralmente, alquiló una casa en el barrio Bretaña. Finalmente, en 1958 adquirió la casa del barrio Miraflores. Allí crió a don Carlos y a sus hermanas.

Carlos, que llegó a Miraflores a la edad de seis años, estudió inicialmente en el San Luis, luego se pasó al colegio El Carmelitano y después al colegio Americano, donde cursó parte del bachillerato. Finalmente terminó sus estudios en el Ceducap y luego estudió algunos semestres de ingeniería eléctrica, pero se retiró y estudió una tecnología en ingeniería de sistemas en el Instituto Camacho Perea.

Debido a las conexiones políticas de su padre, Carlos trabajó 23 años en entidades oficiales: primero en la Oficina de Registro de Instrumentos Públicos y después en las Empresas Municipales de Cali, donde se jubiló en 1999. Nunca se casó, tampoco tuvo hijos y vive actualmente junto con sus hermanas en la casa paterna.

Estas dos historias constituyen una muestra del tipo de familias que pobló el barrio Miraflores a principios de la década de los cincuenta, el cual se caracterizó por una fuerte presencia de extranjeros de origen americano, suizo y alemán. Muchos de ellos llegaron allí atraídos por las oportunidades comerciales que empezaban a gestarse gracias al proceso de industrialización que se desarrollaba en la ciudad y en el país a mediados del siglo XX.

El otro grupo que hizo presencia en el barrio fue el de los profesionales y empleados de entidades del Estado, que, en muchos de los casos, por sus filiaciones políticas lograban conseguir un nombramiento en una institución estatal o desplegar una carrera política que les garantizaba el acceso a puestos públicos para sus copartidarios y familiares.

Es de notar que los hijos de los fundadores realizaron estudios de educación superior y se vincularon laboralmente. En el caso de Isabel, inicialmente a la universidad y después a colegios privados e instituciones de enseñanza de lenguas. Carlos, por su parte, trabajó toda su vida en instituciones del Estado. Por otro lado, mientras que Carlos nunca se casó ni tuvo hijos, los hijos de Isabel siguen una formación profesional y sus hermanas se fueron a vivir a los Estados Unidos, mientras que Carlos y sus hermanas permanecieron en Cali durante y después de la muerte de sus padres. Ambos, Isabel y Carlos, viven en la casa paterna.

\section{Conclusiones}

Desde la década de los veinte, Cali empezó un proceso de reconfiguración socio espacial que se ve reflejado en el uso y la comercialización del suelo urbano, pues se dio inicio a la construcción de barrios residenciales para capas altas y medias, así tersitarios 38

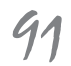


como de barrios de obreros. Todo esto se dio en el marco de un proceso de ampliación y renovación urbana desordenado, que segmentó la ciudad en zonas exclusivas para estas capas sociales: el norte, el oeste y el sur de la ciudad, para capas medias y altas; y el centro y el oriente, para la ubicación de barrios obreros.

Esta nueva división social urbana es el resultado del crecimiento de la población en la ciudad, fruto del desarrollo económico y de la constitución de Cali como capital del departamento del Valle. El aumento de la construcción entre 1920 y 1970 es una clara muestra del proceso de expansión de la ciudad durante el siglo Xx.

El proyecto de la urbanización $\mathrm{Mi}$ raflores, que se desarrolló a finales de la década de los cuarenta, muestra la transformación que empezó a experimentar la ciudad en materia urbana y da cuenta de un claro proceso de segmentación que va a ser ratificado en 1949 por el plano de zonificación de la ciudad que publica la Oficina del Plano adscrita a la administración municipal. En este plano, el sur, el oeste y el norte quedan catalogados como zonas exclusivas, y se ratifica de esta forma el proceso de urbanización informal que habían llevado a cabo las empresas urbanizadoras en la ciudad.

La zona que hoy comprende el barrio Miraflores hizo parte inicialmente de las tierras ejidales que limitaban la antigua ciudad, por eso hay vestigios de un poblamiento inicial que data del siglo XVII. Este proceso se extendió hasta avanzado el siglo XX.
Los $86000 \mathrm{~m}^{2}$ que comprenden el predio de la urbanización Miraflores fueron adquiridos por Egidio Consonni, y constituyeron su principal aporte como socio en la creación de la sociedad Conélica Ltda., firma que urbanizó y comercializó la venta de los lotes. Estos, cuyas áreas oscilaban entre los 300 y los $700 \mathrm{~m}^{2}$, tenían precios que variaban entre los 15 y los 18 pesos por $\mathrm{m}^{2}$.

Pese a la carencia de información sobre los propietarios, el trabajo realizado con algunos de los habitantes del sector, orientado a reconstruir la historia de la urbanización, permitió conocer que entre sus habitantes había comerciantes, empleados y ejecutivos de empresas e industrias de la época. Así mismo, se identificó la presencia de extranjeros de origen suizo, norteamericano y alemán, algunos de los cuales llegaron a la ciudad con las nuevas empresas que se establecían en Cali, y otros eran comerciantes y migrantes que decidieron instalarse en esta región del país.

\section{Referencias}

Aprile-Gniset, J. (2012). Cuatro pistas para un estudio del espacio urbano-caleño. En Historia de Cali Siglo XX, tomo I: Espacio urbano. Cali: Programa editorial Universidad del Valle.

Bermúdez, R. \& Fresneda, O. (2016). Las clases medias urbanas: una aproximación a su medición y caracterización. Ponencia en el XIII Coloquio Colombiano de Sociología, Cali, 7-9 de septiembre.

José Fernando Sánchez Salcedo 
Bourdieu, P. (1990). Espacio social y génesis de clase. En Sociología y cultura. México: Editorial Grijalbo.

Congreso de Empleados de Colombia (1950). Bogotá: Cromos.

Correa, J. J. (2006). Historia local: el ritmo de la historia barrial. Revista Virajes, 8 , 203-223.

Figueroa, E. (2013). Grandes eventos como oportunidades de transformación urbana: los Juegos Panamericanos de Santiago de Cali (Tesis doctoral, Facultad de Arquitectura, Diseño y Estudios Urbanos, Pontificia Universidad Católica de Chile).

Fresneda, O. (2009). Cambios en la estructura socio-ocupacional en Colombia: una exploración con base en fuentes estadísticas (1938-2003). En B. Castro (comp.). La sociedad colombiana, cifras $y$ tendencias. Cali: Programa editorial Universidad del Valle.

Mejía, G. (2000). Los años del cambio. Historia urbana de Bogotá 1820-1910. Bogotá: Centro Editorial Javeriano.

Ocampo, J. A. (1981). El desarrollo de Cali en el siglo xx. En Santiago de Cali, 450 años de historia. Cali: Alcaldía de Cali.

Pacheco, M. (1981). Ejidos de Cali: siglo XIX. En Santiago de Cali, 450 años de historia. Cali: Alcaldía de Cali.

Ramírez, R. (2005). Historia local: experiencias, métodos y enfoques. Medellín: La Carreta.

\section{Otras fuentes}

Archivo Histórico Municipal de Cali.
Archivo personal de la arquitecta Silvia Schiess.

Escritura n. ${ }^{\circ} 1212$ del 21 de abril de 1949, Notaría Primera.

Escritura n. ${ }^{\circ} 1258$ del 21 de abril de 1949, Notaría Primera.

Escritura n. ${ }^{\circ} 1334$ del 5 de mayo de 1949, Notaría Primera.

Escritura n. ${ }^{\circ} 152$ del 10 de enero de 1949, Notaría Primera.

Escritura n. ${ }^{\circ} 1557$ del 27 de mayo de 1949, Notaría Primera.

Escritura n. ${ }^{\circ} 1558$ del 27 de mayo de 1949, Notaría Primera.

Escritura n. ${ }^{\circ} 1559$ del 27 de mayo de 1949, Notaría Primera.

Escritura n. ${ }^{\circ} 1673$ del 7 de junio de 1949, Notaría Primera.

Escritura n. ${ }^{\circ} 1702$ del 10 de junio de 1949, Notaría Primera.

Escritura n. ${ }^{\circ} 1951$ del 2 de julio de 1949, Notaría Primera.

Escritura n. ${ }^{\circ} 197$ del 24 de enero de 1949, Notaría Primera.

Escritura n. ${ }^{\circ} 220$ del 31 de enero de 1950 , Notaría Segunda.

Escritura n. ${ }^{\circ} 407$ del 16 de febrero de 1949, Notaría Primera.

Escritura n. ${ }^{\circ} 1499$ del 28 de julio de 1947 , Notaría Segunda.

Escrituras radicadas en las notarías Primera y Segunda de Cali.

Fondo Consejo - Archivo Histórico Municipal de Cali.

Mapas del taller de reconstrucción propietarios del barrio Miraflores.

Periódico Antorcha. territarias 38

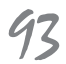


